\title{
Uma Experiência de Formação de Professores no uso de Tecnologias Móveis: A Sala de Aula Expandida com a Plataforma G Suite e Chromebooks
}

\author{
Selma Bessa Sales ${ }^{1}$, Eliziete Nascimento Menezes ${ }^{1}$, Marcos Dionisio Ribeiro do \\ Nascimento ${ }^{1,}$ Wellington Mozarth Moura Maciel $^{2}$, Marcele Aline da Silva \\ Garrido $^{2}$, Daniel Padilha Garrido², José Guilherme Moreira Ribeiro², Caio Julius \\ Mamede Ribeiro ${ }^{2}$ \\ Educacional - Núcleo de Tecnologia Educacional (NTE) Prefeitura Municipal de \\ Fortaleza - Fortaleza, CE - Brasil \\ ${ }^{2}$ Getedu - Google for Education Partner - Brasília, DF - Brasil. \\ selmabessa0808@gmail.com, wellington@getedu.com.br, \\ marcele@getedu.com.br, eliziete30@gmail.com, marcosdionisio@gmail.com, \\ daniel@getedu.com.br, guilherme@getedu.com.br, caio@getedu.com.br
}

\begin{abstract}
This meta-paper presents the experience of teacher training in a Municipal School of Full Time (EMTI) in Fortaleza/CE in the use of the Google for Education тм Platform. The text shows the phases of the training and strategies used for appropriation of knowledge, technological and communicational specificities for the use of the applications (apps) in the classroom. It was evidenced that the course inspires teachers to new pedagogical practices, with the use of mobile devices and cloud computing in addition to establishing the culture of sharing and collaboration.
\end{abstract}

Resumo. Este trabalho apresenta a experiência de formação de professores em uma Escola Municipal de Tempo Integral (EMTI) em Fortaleza/CE no uso da Plataforma Google for Education тм. O texto mostra fases da formação e estratégias utilizadas para apropriação de conhecimentos, especificidades tecnológicas e comunicacionais para aproveitamento dos aplicativos (app's) em sala de aula. Evidenciou-se que o curso inspira os docentes a novas práticas pedagógicas, com o uso de dispositivos móveis e tecnologias em nuvem (cloud computing) além do estabelecimento da cultura do compartilhamento e colaboração.

\section{Introdução}

O objetivo deste trabalho é apresentar a experiência de formação de professores em uma Escola Municipal de Tempo Integral (EMTI) em Fortaleza/CE no uso da Plataforma Google for Education ${ }^{\mathrm{TM}}$ utilizando os chromebooks ${ }^{l}$.

Compreende-se que a formação de professores deve estar fundamentada numa concepção metodológica, que valorize os saberes de experiências construídos ao longo da carreira profissional. Conforme Tardif (2014) os saberes docentes são compostos de

\footnotetext{
${ }^{1}$ Equipamento computacional móvel desenvolvido pelo Google com características específicas para o uso em sala de aula, como duração de bateria e possibilidade de compartilhamento, utilizando o sistema operacional Chrome OS baseado em aplicativos de internet (on-line).
} 
VI Congresso Brasileiro de Informática na Educação (CBIE 2017)

Anais dos Workshops do VI Congresso Brasileiro de Informática na Educação (WCBIE 2017)

saber curricular, saber disciplinar, de formação profissional, saber da experiência, este último muitas vezes desvalorizado, segundo o autor, entre outros vivenciados na prática docente.

A escolha da pesquisa justifica-se a partir da compreensão de que o uso das tecnologias digitais amplia o acesso à informações e à novas formas de comunicação. Nesse aspecto, Moran (2013 p.2) afirma que "as tecnologias móveis desafiam as instituições a sair do ensino tradicional [...], para uma aprendizagem mais participativa e integrada, com momentos presenciais e outros a distância, mantendo vínculos pessoais e afetivos, estando juntos virtualmente".

Outros pesquisadores já desenvolveram trabalhos refletindo sobre o uso de tecnologias móveis por professores da Educação Básica. Como exemplo, temos a experiência de Ferrete e Ferrete $(2015$, p.845), sobre a "necessidade de repensar a abordagem dos conteúdos de ensino, bem como a prática contextualizada e integrada ao uso da tecnologia móvel" ampliando assim a discussão sobre o uso da tecnologia como apoio as atividades pedagógicas integradas ao currículo escolar, cujo objetivo é promover a apropriação da cultura digital na escola.

Diante disso, a questão que se apresenta é: Como auxiliar os professores da EMTI a ampliar as possibilidades de uso das tecnologias na prática docente?

\section{Novas Tecnologias Requerem Novos Letramentos}

Um dos desafios na educação contemporânea está em formar os professores de modo a fazerem uso significativo das potencialidades tecnológicas na realização de suas aulas. A imersão nesse espaço já não é opcional. Mas como incluir a cultura digital na escola?

A cultura digital entra quando mudam-se na escola o espaço, o tempo e o funcionamento, conforme nos explica Fagundes (2011). A questão não é somente colocar computador na escola, em rede e fazer atividades específicas. A ideia de cultura digital é muito mais ampla do que o uso de novas tecnologias. Os educadores precisam se posicionar frente à cultura digital e, para que esse processo se torne realidade, a escola precisa se adaptar à cultura digital.

Em vista disso, pensando na formação, inicial e continuada, onde esse docente possa vivenciar o protagonismo para além do discurso, o protagonismo em ação, oportunizando-o cada vez mais a realizar em sua prática docente aquilo que vivencia durante a formação, Levy (1999) nos chama atenção que é na cibercultura que existe a mudança na relação com o saber, visto que o suporte para o processo cultural está em dispositivos móveis e fixos com interfaces computacionais que ampliam e transformam as funções cognitivas humanas.

Ainda sobre o uso das tecnologias, podemos refletir à luz de Vygotsky sobre a relação desenvolvimento-aprendizagem, pois suas contribuições nos trazem a compreensão de que o meio cultural e a interação social são elementos importantes para o desenvolvimento cognitivo. A mediação também constitui importante conceito da teoria vygotskyana. A partir dela concebemos os ambientes de aprendizagem mediados pelas TIC como facilitadores de trocas entre sujeitos, considerando fundamental o papel exercido pelo mediador nos processos de aprendizagem. (Belloni, 2002, p. 124)

Assim, enquanto sujeito que constrói seu próprio conhecimento o homem age e interage sobre os objetos, através da mediação que, ocorre por meio de ferramentas e de 
VI Congresso Brasileiro de Informática na Educação (CBIE 2017)

Anais dos Workshops do VI Congresso Brasileiro de Informática na Educação (WCBIE 2017)

signos (linguísticos e não-linguísticos) possuidores de significado. Assim, relacionamos à teoria de Vygotsky as ferramentas utilizadas no trabalho com a Plataforma G Suite.

\section{Metodologia}

A Escola Municipal de Tempo Integral de Fortaleza (EMTI) N. Sra. de Fátima, em Fortaleza-CE, é uma escola com práticas articuladas por um Modelo Pedagógico e um Modelo de Gestão, que tem como foco a formação integral do educando, fortalecida na construção do seu Projeto de Vida, essência dos citados modelos e no qual reside a centralidade do currículo em desenvolvimento.

A escola, no ano de 2016, registrou a maior avaliação do Índice de Desenvolvimento da Educação Básica (IDEB), na capital cearense, sendo considerada escola de referência do município. E por ter atingido esse perfil foi selecionada para receber, a primeira sala de inovação educacional com o laboratório piloto do Google.

Além disso, foi proposta a ação de formação para os professores e gestores da escola, totalizando 21 participantes, com mediação da equipe Getedu ${ }^{2}$. O processo foi iniciado em abril de 2017 e término previsto para novembro de 2017.

\subsection{Formação Docente: Desenvolvendo Conhecimentos a Partir de Novos Cenários}

Um dos objetivos do curso foi apoiar e promover a formação continuada de professores para utilizarem os aplicativos da plataforma on-line Google para dar suporte às suas estratégias pedagógicas no ambiente escolar e mudar a rotina em sala de aula. Também é foco da ação a criação de documentos que auxilie a comunidade escolar a estabelecer, critérios, limites, rotinas, etiquetas e outras declarações que tornem o uso das tecnologias transparente, seguro e divertido (sim, a diversão precisa existir).

Toda a formação utiliza a lógica de blended learning e concordando com as ideias de Tori (2006, p.121), dois ambientes de aprendizagem que historicamente se desenvolveram de maneira separada, a tradicional sala de aula presencial e o moderno ambiente virtual de aprendizagem, vêm se descobrindo mutuamente complementares. $\mathrm{O}$ intuito é fazer com que o educador veja exemplos, experimente e se motive para atualizar sua ação docente. O projeto de pesquisa foi submetido ao Comitê de Ética em Pesquisa na Plataforma Brasil.

A ação de formação tem aproximadamente 40 horas/aula (30\% presencial e 70\% a distância), dividida em 4 (quatro) fases e 1 (um) período de operação assistida. Ao final de cada fase é aplicado um formulário de avaliação, a ser preenchido pelos formandos, com finalidade diagnóstica e de satisfação para que seja possível mensurar a eficácia da ação e permitir a evolução contínua da metodologia.

Para cada aplicativo é proposto um projeto, um problema a ser solucionado ou um desafio que fará os professores refletirem nas possibilidades de uso, nas aplicações práticas e nas facilidades que os apps Google podem trazer para as situações de ensino e aprendizagem. O suporte para o uso dos aplicativos é feito utilizando vídeos, textos e dicas disponibilizados por meio do aplicativo Google Classroom. Outro importante vetor de formação é o e-mail dos participantes que semanalmente recebe dicas e atualizações sobre o cenário pedagógico nacional e mundial.

\footnotetext{
${ }^{2}$ Maiores informações <http://geteducacional.com.br>, acesso em maio de 2015.
} 
Ao trabalhar durante a formação com a plataforma do Google for Education ${ }^{\mathrm{TM}} O$ professor inter-relacionou a teoria com a implementação prática na elaboração das atividades didáticas. Ressalta-se que durante o processo de formação os partícipes utilizam os chromebooks ora realizam as atividades individualmente, ora em equipe. $\mathrm{E}$ quando o professor cursista foi solicitado a compartilhar suas experiências, desafios e conquistas com o uso da tecnologia móvel, com o chromebook, a plataforma Google Classroom e os aplicativos declarou que: "a chegada do Google Classroom, ajudou na elaboração do planejamento, nas atividades colaborativas e on-line e nas avaliações no formulário do Google Drive". (Professor A) ${ }^{3}$

\section{Resultados}

Compreende-se com base na análise dos dados, que os docentes da EMTI N. Sra. de Fátima a partir da formação são capazes de integrar os diversos recursos tecnológicos, especialmente, os apps, para expandir o currículo e otimizar o tempo. Além disso, o curso se tornará subsídio considerando a metodologia adotada e as atividades propostas, estimulando-os a pesquisar, estudar e ser autor e coautor na elaboração de atividades agregando as tecnologias e a possibilidade de construção de conhecimento.

A EMTI é uma escola inovadora que, com o empenho de todos, logo poderá se candidatar a ser uma Escola Referência Google 4 e, mais do que isso, conseguirá ver, em prática, os benefícios do uso dos apps com os alunos para inseri-los na cultura do compartilhamento e colaboração.

Percebe-se que os professores e o corpo gestor se mostraram abertos a mudanças e, a partir da primeira formação, já buscaram colocar em prática o que foi ensinado. As notas dos alunos, que anteriormente eram apresentadas no papel para o corpo gestor, agora são compartilhadas em planilhas eletrônicas; uma sala virtual, no aplicativo Google Classroom, serve para a troca de documentos administrativos entre professores e coordenação, facilitando a organização dos arquivos (armazenados no Google Drive); professores aplicam provas on-line, utilizando o Google Formulários, agilizando a rotina de correção de provas e os alunos se interessaram nas atividades postadas pelos professores, realizando-as, inclusive, durante suas férias. Em uma pesquisa ${ }^{5}$ realizada com a comunidade escolar da EMTI 85,7\% dos 21 professores, (18 docentes), apontaram que a Plataforma $G$ Suite facilita a aplicação das atividades pedagógicas em sala de aula e 90,4\%, (19 educadores), afirmaram aumento na frequência de uso de estratégias pedagógicas envolvendo tecnologias após o início da formação da Plataforma $G$ Suite, esse aumento é confirmada por mais de $70 \%$ dos estudantes (259 discentes) que também percebem de maneira unânime o Chromebook como um elemento facilitador no uso das tecnologias se comparado com o computador de mesa (desktop) que compõem o laboratório da escola.

\footnotetext{
${ }^{3}$ Para saber mais sobre o depoimento do professor acesse: https://www.youtube.com/watch?v=Dt8BIQDW4a8, acesso em agosto de 2017.

${ }^{4}$ Maiores informações < https://www.tecmundo.com.br/google/108965-google-brasil-apresenta-tresprimeiras-escolas-referencia.htm $>$, acesso em agosto 2017.

${ }^{5}$ Pesquisa aplicada aos 21 profissionais participantes da formação Getedu e a 370 estudantes, pode ser consultado em: $<$ https://sites.google.com/grupoget.net.br/move-to-getedu-emtinsf $>$, acesso em setembro 2017.
} 
VI Congresso Brasileiro de Informática na Educação (CBIE 2017)

Anais dos Workshops do VI Congresso Brasileiro de Informática na Educação (WCBIE 2017)

\section{Considerações Finais}

O estudo revela que, após participação na formação, o professor aprendeu novas formas de aprender em rede inovando assim sua prática pedagógica. Para tanto, faz-se necessário a utilização dos espaços emergentes pela mobilidade, ubiquidade e os territórios criativos na promoção do uso das tecnologias móveis.

Os docentes demonstraram interesse pelo uso da plataforma G Suíte, em especial no Google Classrom e nos chromebooks, além da conquista de uma postura segura com a nova forma de comunicação e colaboração digital.

Os recursos da plataforma $G$ Suite podem promover, além de ganhos qualitativos, pelo maior engajamento de professores e estudantes, outros resultados positivos como o barateamento de processos de avaliações que podem passar a ser feito eliminando a necessidade de impressão e logística, auxílio nas ações de comunicação, gestão de conhecimento e organização do ambiente escolar, de modo interativo, corroborando com a formação de cidadãos politizados cujos conhecimentos e saberes sejam potencializados e partilhados.

Conectá-los em redes de aprendizado, orientá-los como utilizar as ferramentas e colocar a escola na nuvem para que acessem independente do tempo e do espaço foi uma etapa já concluída sem dúvida. No entanto, não tivemos dados suficientes para avaliar resultados do impacto na aprendizagem dos alunos através dessa estratégia, sendo uma necessidade para um trabalho futuro.

\section{Referências}

Belloni, Maria Luiza (org). A formação na sociedade do espetáculo. Loyola, São Paulo, 2002. p. 119 - 124. Disponível em: < https://goo.g1/USzGLg>, acesso em: Agosto 2017

Fagundes, Léa. Como entra a cultura digital na escola. Universidade Federal do Rio Grande do Sul: 2011. 3:50. Educarede Disponível em: $<$ https://www.youtube.com/watch?v=EAITZRF10bk>, acesso em março 2015.

Ferrete, A. A. S. S; Ferrete, R. B. As tecnologias móveis na formação docente. Anais dos Workshops do IV Congresso Brasileiro de Informática na Educação. CBIE 2015. Disponível em: < http://www.br-ie.org/pub/index.php/wcbie/article/view/6129> Acesso em janeiro de 2017.

Levy. P. Cibercultura. São Paulo Editora 34, 1999.

Moran J.M. "Novas Tecnologias e Mediação Pedagógica", Papirus, 21ª ed., 2013, p.3035 (texto ampliado) Disponível em: <http://www2.eca.usp.br/moran/wpcontent/uploads/2013/12/tabletseduc.pdf $>$, acesso em julho 2017 .

Tardif, Maurice. Saberes docentes e formação profissional. 17. ed. Petrópolis, RJ: Vozes, 2014

Tori, R. Cursos híbridos ou blended learning. In: FORMIGA, M e LITTO, F. Educação a distância: o estado da arte. São Paulo: Pearson Education, 2009. 